\title{
ROUGHNESS EVOLUTION OF PREVIOUSLY MILLED SAMPLES ALONG A POLISHING TEST
}

\author{
Irene Buj-Corral ${ }^{1, *}$ Joan Vivancos-Calvet ${ }^{1}$ \\ ${ }^{1}$ Dpt. of Mechanical Engineering, Universitat Politècnica de Catalunya, Av. Diagonal, 647, 08028 Barcelona, \\ Spain. *Corresponding author. Tel. +34934054016. Fax. +34934016693. \\ E-mail address: irene.buj@upc.edu, irene.buj@gmail.com (I. Buj), joan.vivancos@upc.edu (J. Vivancos)
}

\begin{abstract}
In the present work results about roughness evolution along a polishing operation with corundum disks of size Norton 400 are presented. Hardened steel and hardened stainless steel samples were previously subjected to ball-end milling or side milling with cylindrical tool at different cutting conditions. Roughness height parameters $R a$ and $R t$, as well as parameters related to the Abbott-Firestone curve such as $R k, R p k$ and $R v k$, and shape parameters like Rsk and $R k u$ were studied. It is usually considered that a polishing operation is finished when $R a$ does not decrease significantly with more polishing time. In the present paper, an alternative method for determining the end of a polishing test is presented. Roughness is measured both in the longitudinal and in the transversal direction with respect to cutting marks, and it is assumed that the polishing operation is finished when longitudinal values equal transversal values, provided that from that moment on roughness values do not decrease in a significant way. Moreover, it is recommended to measure parameter $R v k$ in addition to or even instead $R a$, in order to obtain information about the presence of valleys from the previous milling operation.
\end{abstract} Keywords: milling; polishing; roughness; steels; corundum; feed; depth; time

\section{Introduction}

Ball-end milling cutters are often employed in the machining process of sculptured surfaces such as those obtained in the manufacturing process of molds [1] and dies [2]. Different surface roughness values are achieved depending on milling cutting parameters such as radial depth of cut $R d$ or feed per tooth and revolution $f$. Moreover, shape of surface topography will depend on $f / R d$ ratio. At low $f / R d$ ratio, parallel tool marks are obtained. On the contrary, at high $f / R d$ ratio, cusps on the machined surface are observed [3]. Side milling with cylindrical tool is also typically used to manufacture molds and dies, for example in vertical walls, cavities or pockets. Main parameter influencing surface roughness in side milling is feed per tooth $f$ [4]. When low surface roughness of molded parts is required a polishing operation is often performed after milling and/or electro discharge machining. It is possible to use machines for polishing. However, they are mainly prepared for polishing flat, cylindrical and/or spherical surfaces [5]. For this reason, nowadays in industry manual polishing is still performed in most cases. When the manufacturing process of a mold is considered, total machining time comprises both milling and polishing time. For this reason, it is important to focus on the polishing operation so as to select most appropriate milling cutting conditions that will minimize total machining time.

Polishing is included within abrasive machining processes, in which small abrasive particles remove material from workpieces' surface [6]. Several parameters influence roughness and material removal rate in polishing 
operations. Lin and $\mathrm{Wu}$ polished $\mathrm{Al}$ disks plated with a Ni-P layer. They noted that material removal rate increased with pressure and with relative velocity between sample and polishing pad [7]. Chang et al. polished steel gauge blocks with either $\mathrm{SiC}$ or $\mathrm{Al}_{2} \mathrm{O}_{3}$ and found that surface roughness increased with grain size, abrasive concentration and pressure [8]. When polishing ceramic blocks, Huang et al. found that load, speed, grain size and diamond concentration increased material removal rate. Surface roughness decreased with polishing time and speed, while it increased with abrasive concentration and abrasive grain size. Load did not influence roughness significantly [9]. Mohan et al. found extremely low roughness values on metallic surfaces obtained by means of a cryogenic polishing tool in which ice bonds abrasive particles [10]. Sun et al. polished silicon wafers with the same technique. They found that most influential parameters on surface roughness were polishing time and table velocity [11].

Curves obtained when plotting average roughness $R a$ vs. polishing time are generally exponential, showing a rapid roughness reduction in the first stages. Later, it becomes steady showing a saturation effect where it is not possible to reduce roughness significantly with more polishing time. Thus, a polishing test is considered to be finished after a certain average roughness $R a$ value, which is related to the grain size of the polishing material, is attained [12]. However, roughness values in many machined surfaces, such as milled ones, depend greatly on the measuring direction. On the other hand, few authors have employed other roughness parameters different than $R a$ for characterizing polished surfaces and the end of a polishing test. De Chiffre et al. studied areal parameters related to Abbott-Firestone curve, Sk, Spk, Svk for hardened steel tool specimens. They showed a decreasing trend with polishing time for high grain size, although for low grain size, roughness parameters remained almost constant with polishing time in general [13]. Grzesik and Zak compared different roughness parameters (Ra, Rsk, Rku,Rsm, etc.), as well as Abbott-Firestone or bearing curves of turned samples and of samples subjected to superfinishing and burnishing operations. They observed negative skew in superfinished surfaces after turning [14].

In many industrial companies only 2D roughness measurements can be performed. In the present work, behavior of several roughness parameters ( $R a, R t, R k, R p k, R v k, R k u$ and $R s k$ ) with polishing time is studied, for samples previously milled at different cutting conditions. In addition, a new alternative method for determining the required time for polishing a sample is presented.

\section{Materials and methods}

\subsection{Materials}

Ball-end milling and side milling operations were performed on hardened steel WNr. 1.2344 blocks (HRC 54) an on hardened stainless steel WNr.12083 blocks (HRC 52). Selected steel are used for manufacturing injection molds and forging dies respectively. Other materials such as B20 bell metal bronze and 7075 aluminum were also tested. However, both of them are ductile materials that become polished in $10 \mathrm{~s}$ or less. For this reason, obtained results are not presented in the present paper. Dimension of milled area on the blocks' surface was 66 x $6 \mathrm{~mm}$ while dimension of polished area was $30 \times 6 \mathrm{~mm}$.

\subsection{Methods}




\section{Milling operations}

Milling operations were performed in a vertical Mori-Seiki Dura machining center. Air cooling was used in all cases. Machining parameters were selected according to manufacturer's recommendation and previous tests. In ball-end milling operations, $6 \mathrm{~mm}$ diameter tools having 2 cutting edges were selected. Cutting speed was 180 $\mathrm{m} \cdot \mathrm{min}^{-1}$ and axial depth of cut was $0.15 \mathrm{~mm}$. Both radial depth of cut $R d$ and feed $f$, which are the most influent parameters on roughness [15], were varied (Table 1). In side milling operations, $6 \mathrm{~mm}$ diameter tools having 6 teeth were selected. Cutting speed was $180 \mathrm{~m} \cdot \mathrm{min}^{-1}$ and radial depth of cut was $0.15 \mathrm{~mm}$. Feed $f$, which is the most influential parameter on roughness [4], was varied (Table 1). Milling experiments were named with a consecutive number between 1 and 6 followed by a letter $\mathrm{S}$ for steel or by a letter I for stainless steel. A schematic representation of the milling operations performed is presented in Figure 1.

Figure 1 Schematic representation of: a) ball-end milling operation, b) side milling operation.

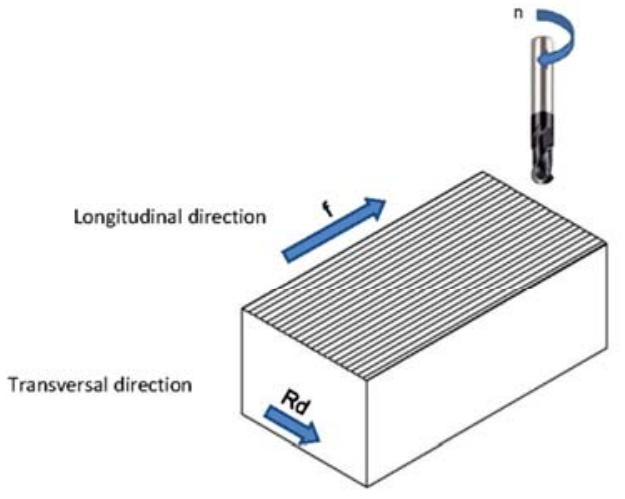

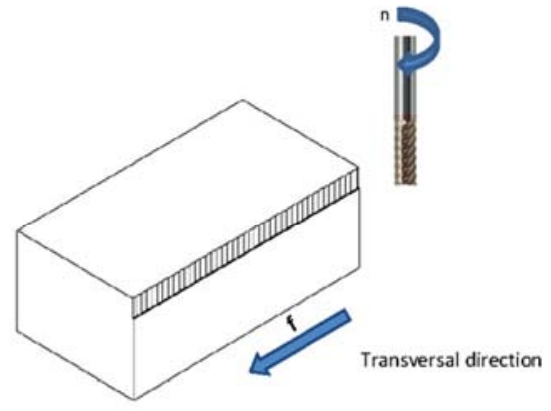

b

Performed experiments are listed in Table 1.

Table 1 Experiments performed

\begin{tabular}{|l|l|l|l|l|}
\hline EXPERIMENT & $\begin{array}{l}\text { MACHINED } \\
\text { MATERIAL }\end{array}$ & $\begin{array}{l}\text { MILLING } \\
\text { TOOL }\end{array}$ & $\begin{array}{l}\text { RADIAL DEPTH } \\
\text { OF CUT }\end{array}$ & $\begin{array}{l}\text { FEED PER } \\
\text { TOOTH }\end{array}$ \\
\hline $1 \mathrm{~S}$ & Steel & Ball-end & 0.40 & 0.05 \\
\hline $2 \mathrm{~S}$ & Steel & Ball-end & 0.40 & 0.40 \\
\hline $3 \mathrm{~S}$ & Steel & Ball-end & 0.25 & 0.05 \\
\hline $4 \mathrm{~S}$ & Steel & Ball-end & 0.25 & 0.40 \\
\hline $5 \mathrm{~S}$ & Steel & Cylindrical & 0.15 & 0.02 \\
\hline $6 \mathrm{~S}$ & Steel & Cylindrical & 0.15 & 0.06 \\
\hline $1 \mathrm{I}$ & Stainless steel & Ball-end & 0.40 & 0.05 \\
\hline 2I & Stainless steel & Ball-end & 0.40 & 0.40 \\
\hline $3 \mathrm{I}$ & Stainless steel & Ball-end & 0.25 & 0.05 \\
\hline $4 \mathrm{I}$ & Stainless steel & Ball-end & 0.25 & 0.40 \\
\hline $5 \mathrm{I}$ & Stainless steel & Cylindrical & 0.15 & 0.02 \\
\hline $6 \mathrm{I}$ & Stainless steel & Cylindrical & 0.15 & 0.06 \\
\hline
\end{tabular}




\section{Polishing operations}

Polishing operations were conducted in an automatic Mecapol P230 polishing machine, with corundum polishing disks of grain size 400, which is a usual grain size for rough polishing of molds. Speed of polishing pad was $50 \mathrm{~min}^{-1}$. Samples were held on a polishing head which rotates, in order to compensate radial distance on the polishing disk. Low pressure corresponding to $1.5 \mathrm{daN}$ force was chosen so as to assure a certain polishing time before the sample is completely polished. Elemental test time was $10 \mathrm{~s}$ and total polishing time was $60 \mathrm{~s}$ ( 6 consecutive polishing operations).

\section{Roughness measurements}

Roughness was measured by means of a contact roughness meter Taylor Hobson Taylsurf Series 2, $\mu$ ltra software (v. 4.6.8). Roughness parameters measured were Ra, Rt, $R k, R p k, R v k, R k u$ and Rsk. In addition, Abbott-Firestone curve was obtained. Roughness was measured on milled samples as well as on polished samples along the polishing test. An average value of ten measurements in the longitudinal direction of the milling marks was calculated (longitudinal roughness). An average value of five measurements in the transversal direction was calculated (transversal roughness). For milled samples 3D roughness measurement was also performed, in order to know the shape of the initial surface to be polished.

\section{Photographs}

40x photographs were taken on the workpieces' surface by means of a Leyca S8AP0 magnifier at different stages of the polishing test.

\section{Results}

\subsection{Milled samples}

In Figure 2, as an example, surface topography and a roughness profile in the transversal direction are shown for each milling experiment performed in steel. Similar results were obtained for stainless steel.

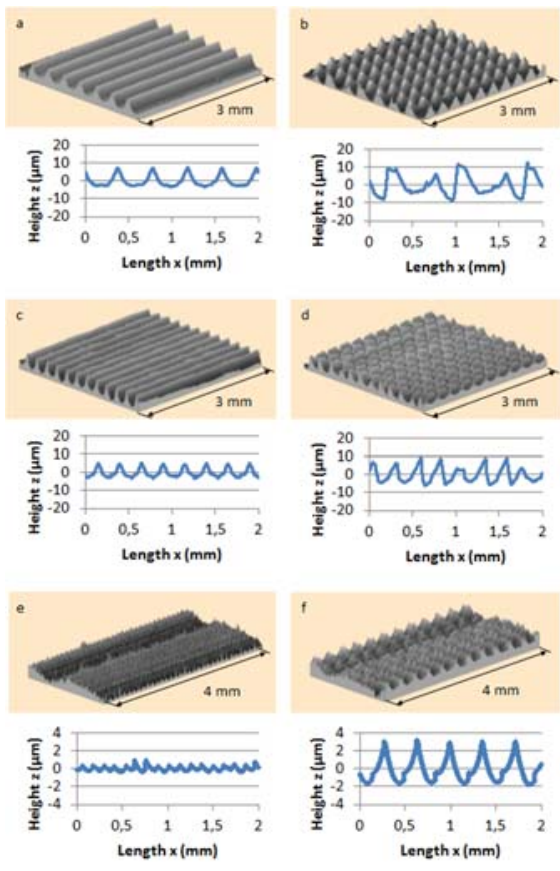


Figure 2. Surface topography and transversal roughness profiles for experiments: a) $1 \mathrm{~S}$, b) $2 \mathrm{~S}$, c) $3 \mathrm{~S}$, d) $4 \mathrm{~S}$, e) $5 \mathrm{~S}, \mathrm{f}) 6 \mathrm{~S}$.

In ball-end milling, at low feed $f$ (Figures 2a and 2c) parallel tool marks were obtained on the workpieces' surface in the feed or longitudinal direction, while at high feed $f$ (Figures $2 \mathrm{~b}$ and $2 \mathrm{~d}$ ) cusps were formed. The type of topography obtained will determine the shape of the roughness profiles as well as of roughness parameters values [16]. At low $f$, roughness profiles in the transversal direction are regular (Figures 2a and 2c), while at high $f$ profiles are less regular (Figures $2 \mathrm{~b}$ and $2 \mathrm{~d}$ ). In side milling, at low feed $f$ (Figure 2e) parallel cutting marks are obtained. At high feed $f$ (Figure 2f), also parallel cutting marks are obtained, although with higher peaks as expected.

\subsection{Evolution of roughness parameters and of Abbott-Firestone curve}

Only results for hardened steel are shown in the present section, since similar results were obtained for hardened stainless steel.

\section{Height parameters $R a, R t$.}

In Figure 3 height parameters are presented both in the transversal and in the longitudinal direction as a function of polishing time.
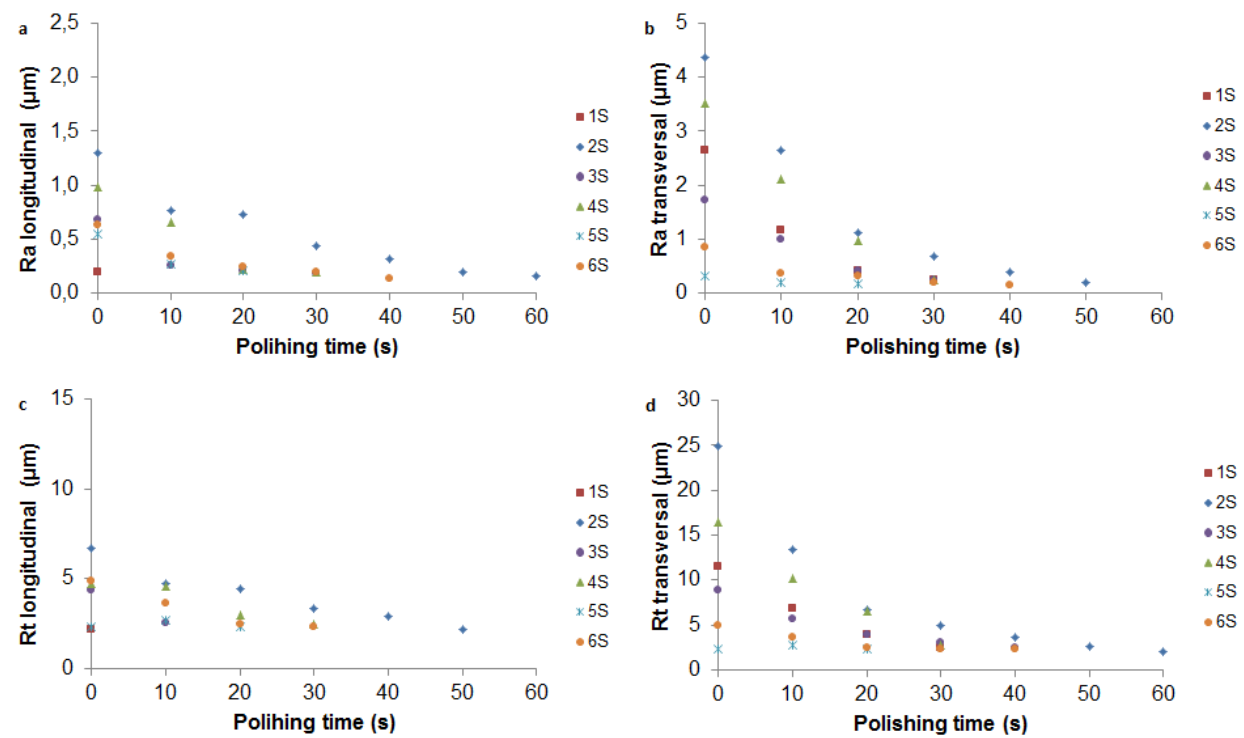

Figure 3. Evolution of height roughness parameters with time, for all experiments performed: a) $R a$ longitudinal, b) $R a$ transversal, c) $R t$ longitudinal, d) $R t$ transversal

For milled samples (polishing time $0 \mathrm{~s}$ ), values of height roughness parameters depend on cutting conditions employed. In the transversal direction, experiments at high $f$ have higher roughness values than experiments at low $f$ (Figures 3b and 3d). Results obtained in the longitudinal direction (Figures 3a and 3c) follow a similar trend to those obtained in the transversal direction, although with lower roughness values. 
Along the polishing operations, parameters $R a$ and $R t$ in the transversal direction decrease according to an exponential curve (Figures $3 \mathrm{~b}$ and $3 \mathrm{~d}$ ). The same parameters only slightly decrease if longitudinal measurements are considered (Figures $3 \mathrm{a}$ and $3 \mathrm{c}$ ).

\section{Bearing area parameters $R k, R p k, R v k$.}

In Figure 4 results for parameters $R k, R p k$ and $R v k$ (longitudinal and transversal measurements) are shown, at different polishing times. Core roughness $R k$, reduced peak height $R p k$ and reduced valley depth $R v k$ are related to the material percentage or Abbott-Firestone curve [17].
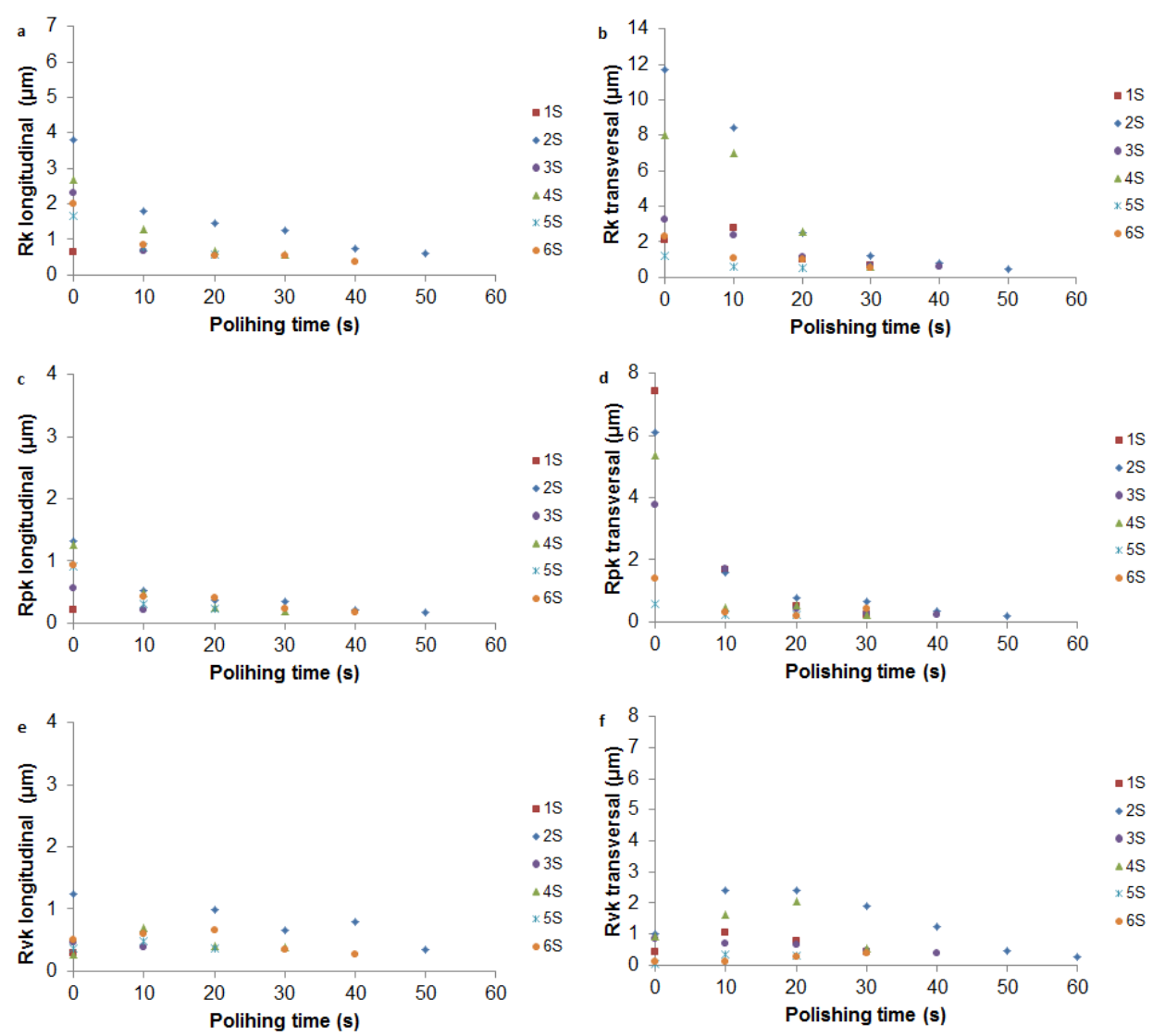

Figure 4. Evolution of roughness bearing area parameters with time, for all experiments performed: a) $R k$ longitudinal, b) $R k$ transversal, c) $R p k$ longitudinal, d) $R p k$ transversal, e) $R v k$ longitudinal, f) $R v k$ transversal

Regarding milled samples (polishing time $0 \mathrm{~s}$ ), most influential parameter on $R k$ in the transversal direction is $f$ (Figure $4 \mathrm{~b}$ ), as it was for $R a$ and $R t$, due to the change on topography that is produced between low $f$ (Figures $2 \mathrm{a}$ and $2 \mathrm{c}$ ) and high $f$ (Figures $2 \mathrm{~b}$ and $2 \mathrm{~d}$ ). On the contrary, as for Rpk in the transversal direction, at low $f$ the effect of $R d$ is remarkable (Figure $4 \mathrm{~d}$ ). At high $R d$, tool marks are wider than at low $R d$, crests that limit longitudinal tool marks are higher and so is Rpk. Parameters $f$ and $R d$ have little effect on $R v k$ in the transversal direction (Figure 4f). Similar results were obtained for $R k$, Rpk and $R v k$ regarding longitudinal roughness (Figures 4a, 4c and 4e) for all experiments performed, albeit with lower initial roughness values. 
Concerning the polishing test, transversal roughness $R k$ decreases significantly during the first 20 seconds for experiments at high $f$, while it increases or decreases a little for experiments milled at low $f$ (Figure $4 b$ ).

Transversal roughness $R p k$ drops sharply between 0 and 10 seconds, and then it decreases more smoothly (Figure 4d). Transversal roughness $R v k$ first increases. This is due to the fact that, in initial polishing stages, abrasive grains remove roughness peaks, so that valleys become more important than peaks. Afterwards, $R v k$ decreases slightly (Figure 4f). As a general trend, in the longitudinal direction roughness parameters $R k$ and $R p k$ decrease slightly with polishing time, while $R v k$ first decreases and then increases with polishing time (Figures 4a, 4c and 4e).

\section{Amplitude distribution parameters Rku, Rsk}

Since height and bearing area parameters in the longitudinal direction do not change significantly with time along the polishing operation, only results in the transversal direction are shown here for amplitude distribution parameters $R k u$ and Rsk (Figure 5).
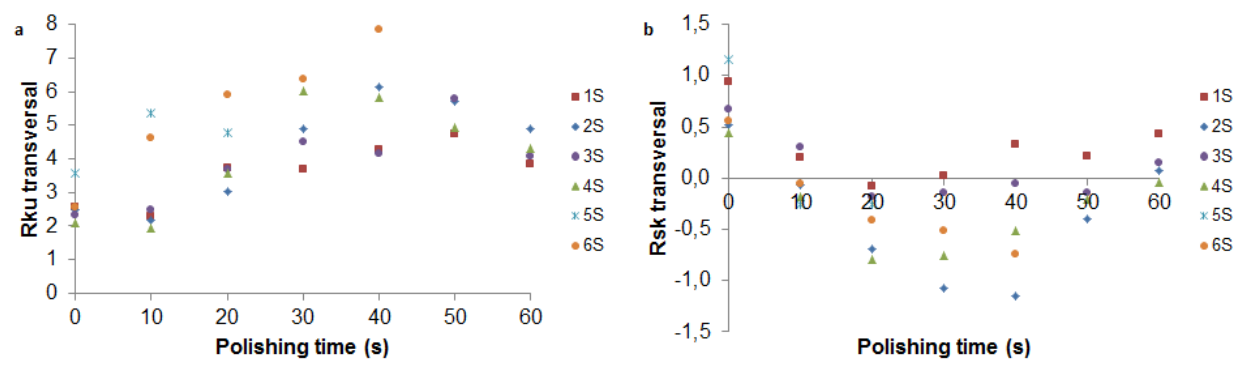

Figure 5. Evolution of amplitude distribution roughness parameters with time in the transversal direction, for all experiments considered: a) $R k u$, b) Rsk

For milled samples (polishing time $0 \mathrm{~s}$ ), kurtosis $R k u$, which is a measure of the peakedness of the probability distribution of roughness heights, has a value between 2 and 4 (Figure 5a). A value of 3 corresponds to a normal distribution. Positive skewness Rsk, which is related to symmetry of the profile, was found for all milled samples (Figure 5b), showing higher peaks than valleys. Low kurtosis and positive skew are typical of machining processes like turning or milling [18].

For polished samples, kurtosis $R k u$ takes a value that is higher than 3 from $20 \mathrm{~s}$ on, with values up to 6 . During the first stages of polishing operations, kurtosis is higher for side milled samples than for ball-end milled samples, showing a sharper distribution for the former than for the latter. In all cases, roughness distributions are more acute than the normal one. Regarding skewness Rsk, it decreases during the first stages of the polishing operation and then increases again. For samples obtained at high $f$, skewness remains between -0.1 and 0.5 . For samples obtained at low $f$, skewness remains between -1.3 and +0.1 . Such results are similar to those reported by Grzesik for grinding operations, with high kurtosis and negative skew [18].

\section{Abbott-Firestone curves}


Figure 6 depicts the evolution of Abbott-Firestone curves in the transversal direction along the polishing test. Material percentage of $90 \%$ was taken into account for comparison of different curves [19].
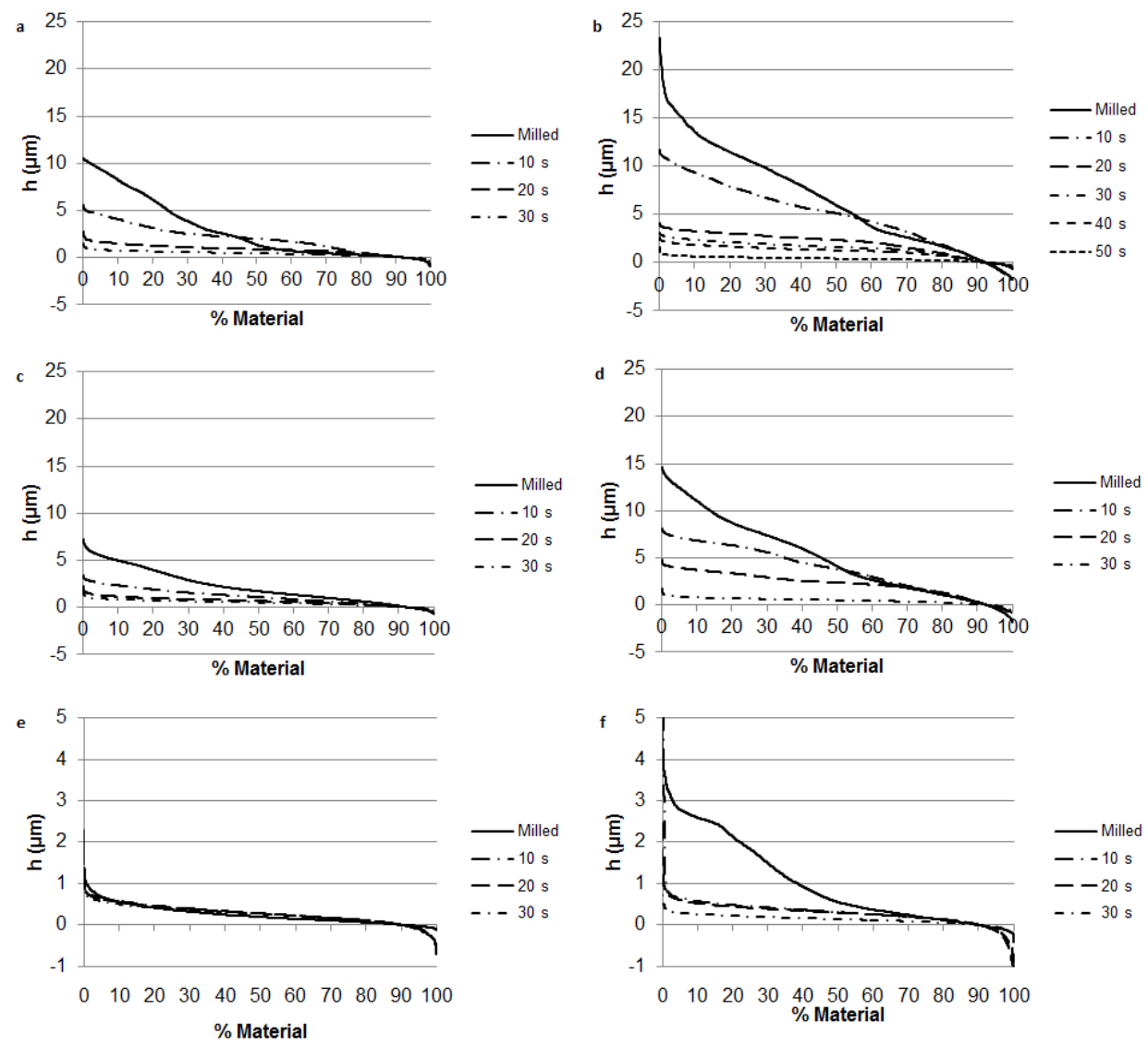

Figure 6. Abbott-Firestone curves in the transversal direction for experiments: a) 1S, b) 2S, c) 3S, d)

$$
4 \mathrm{~S}, \text { e) } 5 \mathrm{~S}, \mathrm{f}) 6 \mathrm{~S}
$$

For ball-end milled samples, highest curves correspond to high $f$ (Figures 6b and 6d) with a topography that is characterized by a distribution of cusps (Figures $2 \mathrm{~b}$ and $2 \mathrm{~d}$ ). Lowest curves correspond to low $f$ (Figures 6a and 6c) with topography of parallel crests (Figures $2 \mathrm{a}$ and $2 \mathrm{c}$ ). Abott-Firestone curve for experiment $2 \mathrm{~S}$ shows a sharp slope in the beginning because of some peaks that are higher than the rest of peaks in the roughness profile (Figure 2b). For experiments $1 \mathrm{~S}, 3 \mathrm{~S}$ and $4 \mathrm{~S}$ curves for the milled samples have almost linear shape. For all milled samples, central part of the Abbott-Firestone curve is inclined (Figures 6a, 6b, 6c and 6d), which corresponds to profiles with $R k u=3$ (Figure 6a) [20].

For side milled samples roughness is quite low, although it is higher for experiment 6S (Figure 6f), machined at higher feed, than for experiment 5S (Figure 6e), obtained at lower feed. Abbott-Firestone curve for experiment 6S shows a sharp slope in the beginning (Figure 6f).

As the polishing test proceeds, total height of the curves decreases. In addition, slope of the central part of the Abbott-Firestone decreases (Figures 6a, 6b, 6c, 6d, 6e and 6f), as Rku increases (Figure 6a) [20]. 


\subsection{Evolution of Ra for different materials}

For comparison, roughness results for parameter Ra obtained in steel and stainless steel are presented in Figure 7.
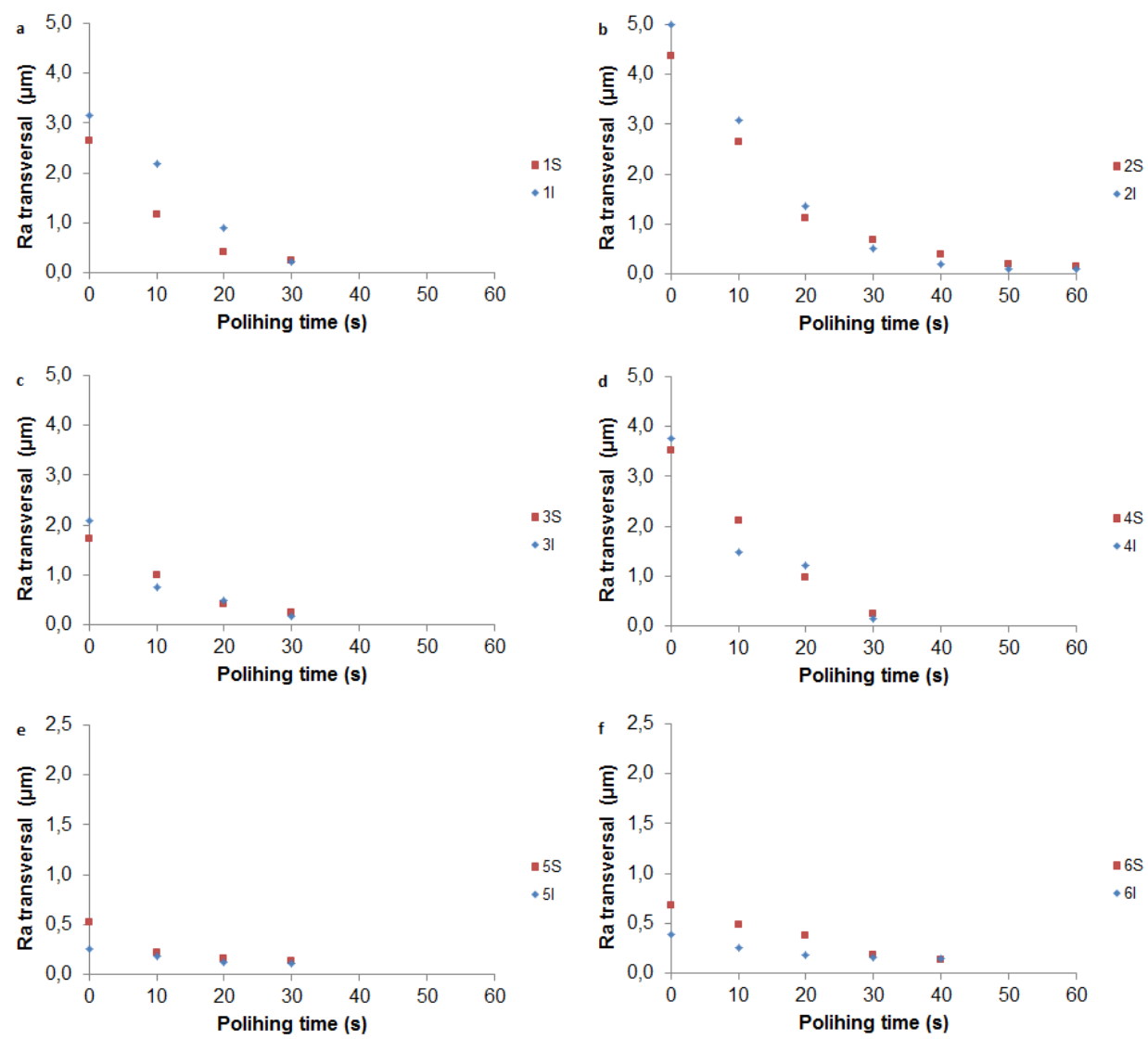

Figure 7 Evolution of roughness Ra for experiments: a) 1S and 1I, b) $2 \mathrm{~S}$ and 2I, c) $3 \mathrm{~S}$ and 3I, d) 4S and 4I, e) $5 \mathrm{~S}$ and $5 \mathrm{I}, \mathrm{f}) 6 \mathrm{~S}$ and $6 \mathrm{I}$

Figure 7 shows that, in experiments with ball-end milling, initial roughness Ra is slightly higher for stainless steel than for steel. On the contrary, for experiments with cylindrical milling tool, initial roughness Ra is slightly higher for steel than for stainless steel. As a general trend, curves representing Ra with polishing time are alike, with similar polishing times.

\subsection{Determination of polishing time}

In the literature, a polishing operation is considered to be finished when average roughness $\mathrm{Ra}$ does not decrease remarkably with more polishing time [11], while measuring direction is not specified. However, machining tools leave marks on the work pieces' surface. For this reason, roughness measurements are different depending on measurement direction. In summary, marks produced by milling tools are directional while marks produced by polishing pads follow random directions. This observation suggests that successive 
polishing operations will remove prior milling marks, starting with the peaks and continuing with valleys. This will result in the presence of randomly distributed polishing marks. As an example, Figure 8 shows the evolution of the surface topography of experiment $2 \mathrm{~S}$. Initial topography presents peaks and valleys, specifically parallel tool marks with cusps (Figure 8a) As the polishing test proceeds, first summits of the roughness topography are removed (Figure $8 b$ ). Then the whole peaks are smoothed and only valleys remain (Figure 8c). Polishing operation progressively removes previous milling marks, which are directional, while polishing marks, which are non-directional and randomly distributed, prevail (Figure 8d), until only polishing marks are observed (Figures $8 \mathrm{e}, 8 \mathrm{f}$ and $8 \mathrm{~g}$ ).

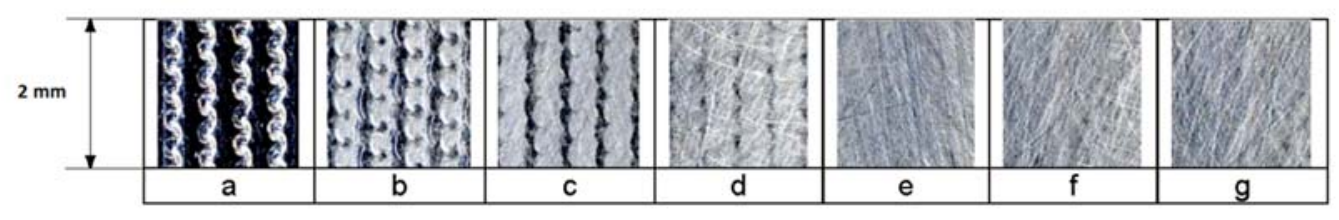

Figure $8.40 \mathrm{x}$ photographs of experiment $2 \mathrm{~S}$ at different polishing times: a) $0 \mathrm{~s}, \mathrm{~b}) 10 \mathrm{~s}, \mathrm{c}) 20 \mathrm{~s}$, d) $30 \mathrm{~s}$, e) $40 \mathrm{~s}$, f) $50 \mathrm{~s}, \mathrm{~g}) 60 \mathrm{~s}$

According to the progress of the polishing test, in the present work a surface was considered to be completely polished when longitudinal roughness value equals transversal roughness value, and roughness values do not decrease significantly with polishing time. This criterion was called LT. Alternatively, a polishing test can be considered to be finished when either transversal roughness (criterion $\mathrm{T}$ ) or longitudinal roughness (criterion $\mathrm{L}$ ) do not decrease with time.

In Table 2 results for the twelve experiments considered concerning criteria LT, T and L for different roughness parameters are presented for comparison.

Table 2. Polishing time $\mathrm{t}(\mathrm{s})$ according to criteria $\mathrm{LT}, \mathrm{L}$ and $\mathrm{T}$

\begin{tabular}{|l|c|c|c|c|c|c|}
\hline Experiment & Criterion & $\mathrm{t}(\mathrm{s}) \mathrm{Ra}$ & $\mathrm{t}(\mathrm{s}) \mathrm{Rt}$ & $\mathrm{t}(\mathrm{s}) \mathrm{Rk}$ & $\mathrm{t}(\mathrm{s}) \mathrm{Rpk}$ & $\mathrm{t}(\mathrm{s}) \mathrm{Rvk}$ \\
\hline 1S & $\mathrm{LT}$ & 30 & 30 & 30 & 30 & 40 \\
& $\mathrm{~L}$ & 0 & 0 & 0 & 0 & 20 \\
& $\mathrm{~T}$ & 30 & 30 & 30 & 30 & 40 \\
\hline 2S & $\mathrm{LT}$ & 50 & 60 & 50 & 50 & 60 \\
& $\mathrm{~L}$ & 50 & 50 & 50 & 40 & 50 \\
& $\mathrm{~T}$ & 50 & 60 & 50 & 50 & 60 \\
\hline $3 \mathrm{~S}$ & $\mathrm{LT}$ & 30 & 40 & 30 & 30 & 40 \\
& $\mathrm{~L}$ & 20 & 10 & 10 & 10 & 20 \\
& $\mathrm{~T}$ & 30 & 40 & 30 & 30 & 40 \\
\hline $4 \mathrm{~S}$ & $\mathrm{LT}$ & 30 & 30 & 30 & 30 & 40 \\
& $\mathrm{~L}$ & 30 & 20 & 20 & 20 & 20 \\
& $\mathrm{~T}$ & 30 & 30 & 30 & 30 & 40 \\
\hline
\end{tabular}




\begin{tabular}{|c|c|c|c|c|c|c|}
\hline $5 \mathrm{~S}$ & $\begin{array}{c}\mathrm{LT} \\
\mathrm{L} \\
\mathrm{T}\end{array}$ & $\begin{array}{l}30 \\
20 \\
10\end{array}$ & $\begin{array}{l}20 \\
20 \\
20\end{array}$ & $\begin{array}{l}30 \\
20 \\
10\end{array}$ & $\begin{array}{l}30 \\
20 \\
30\end{array}$ & $\begin{array}{l}30 \\
30 \\
30\end{array}$ \\
\hline $6 \mathrm{~S}$ & $\begin{array}{c}\text { LT } \\
\text { L } \\
\mathrm{T}\end{array}$ & $\begin{array}{l}30 \\
30 \\
30\end{array}$ & $\begin{array}{l}40 \\
40 \\
40\end{array}$ & $\begin{array}{l}30 \\
30 \\
20\end{array}$ & $\begin{array}{l}40 \\
20 \\
30\end{array}$ & $\begin{array}{l}40 \\
40 \\
40\end{array}$ \\
\hline 1I & $\begin{array}{c}\mathrm{LT} \\
\mathrm{L} \\
\mathrm{T}\end{array}$ & $\begin{array}{l}40 \\
20 \\
40\end{array}$ & $\begin{array}{c}40 \\
0 \\
30\end{array}$ & $\begin{array}{l}40 \\
10 \\
30\end{array}$ & $\begin{array}{l}40 \\
40 \\
40\end{array}$ & $\begin{array}{l}40 \\
20 \\
40\end{array}$ \\
\hline $2 \mathrm{I}$ & $\begin{array}{c}\mathrm{LT} \\
\mathrm{L} \\
\mathrm{T}\end{array}$ & $\begin{array}{l}60 \\
40 \\
40\end{array}$ & $\begin{array}{l}50 \\
40 \\
30\end{array}$ & $\begin{array}{l}60 \\
40 \\
40\end{array}$ & $\begin{array}{l}30 \\
30 \\
30\end{array}$ & $\begin{array}{l}60 \\
40\end{array}$ \\
\hline $3 \mathrm{I}$ & $\begin{array}{c}\mathrm{LT} \\
\mathrm{L} \\
\mathrm{T}\end{array}$ & $\begin{array}{l}30 \\
20 \\
30\end{array}$ & $\begin{array}{l}30 \\
20 \\
30\end{array}$ & $\begin{array}{l}30 \\
20 \\
30\end{array}$ & $\begin{array}{l}40 \\
40 \\
40\end{array}$ & $\begin{array}{l}40 \\
20\end{array}$ \\
\hline $4 \mathrm{I}$ & $\begin{array}{c}\mathrm{LT} \\
\mathrm{L} \\
\mathrm{T}\end{array}$ & $\begin{array}{l}30 \\
30 \\
30\end{array}$ & $\begin{array}{l}40 \\
30 \\
30\end{array}$ & $\begin{array}{l}30 \\
30 \\
30\end{array}$ & $\begin{array}{l}30 \\
30 \\
30\end{array}$ & $\begin{array}{l}40 \\
30 \\
40\end{array}$ \\
\hline $5 \mathrm{I}$ & $\begin{array}{c}\mathrm{LT} \\
\mathrm{L} \\
\mathrm{T}\end{array}$ & $\begin{array}{l}10 \\
10 \\
10\end{array}$ & $\begin{array}{l}20 \\
20 \\
10\end{array}$ & $\begin{array}{l}10 \\
10 \\
10\end{array}$ & $\begin{array}{l}20 \\
20 \\
20\end{array}$ & $\begin{array}{l}20 \\
10\end{array}$ \\
\hline $6 \mathrm{I}$ & $\begin{array}{c}\text { LT } \\
\text { L } \\
\mathrm{T}\end{array}$ & $\begin{array}{l}20 \\
20 \\
20\end{array}$ & $\begin{array}{l}20 \\
20 \\
20\end{array}$ & $\begin{array}{l}20 \\
20 \\
20\end{array}$ & $\begin{array}{l}30 \\
30 \\
30\end{array}$ & $\begin{array}{l}30 \\
30\end{array}$ \\
\hline
\end{tabular}

Regarding criterion $\mathrm{L}$, for samples milled at low feed $f$, polishing time values are too low compared to polishing times obtained with criteria T and LT. Since roughness measurements are performed along cutting marks, roughness values of milled samples in the longitudinal direction are quite low and do not vary significantly along the polishing test. For this reason, criterion $\mathrm{L}$ is not recommended for determining the end of a polishing test.

When criterion $\mathrm{T}$ is considered, results are more representative of the polishing test, since roughness profiles measured are perpendicular to cutting marks polishing time. However, for some experiments and roughness parameters, polishing time obtained is slightly lower than that obtained with criterion LT. For example, for experiment $1 \mathrm{I}$, polishing time is $30 \mathrm{~s}$ according to parameter Rt and criterion $\mathrm{T}$, while it is $40 \mathrm{~s}$ according to the same parameter and criterion LT.

As for criterion LT, as a general trend, similar results were obtained for all roughness parameters considered. Polishing time obtained with criterion LT is equal or higher than polishing time obtained with criterion T in all cases. With this criterion, it is assured that previous milling marks are removed, when roughness in the longitudinal direction equals roughness in the transversal one. For this reason, criterion LT is recommended. 
Regarding alternative roughness parameters different than $R a$ to be considered, parameter $R v k$ gives longer polishing time than $R a$ in most cases (experiments 1S, 2S, 3S, 4S, 6S, 3I, 4I, 5I and 6I). Parameter $R t$ gives longer polishing time than $R a$ in some cases (experiments $2 \mathrm{~S}, 3 \mathrm{~S}, 6 \mathrm{~S}, 4 \mathrm{I}$ and $5 \mathrm{I}$ ), while it gives shorter polishing time than $R a$ in some other cases (experiments $5 \mathrm{~S}$ and 2I). Parameter Rpk provides longer polishing time than $R a$ for experiments $6 \mathrm{~S}, 3 \mathrm{I}$ and $6 \mathrm{I}$, and shorter polishing time than $R a$ for experiments $2 \mathrm{I}$ and 5I. Thus, parameter $R v k$ ensures that polishing time is long enough to allow that all previous marks have been removed. For this reason, parameter $R v k$ is recommended for determining polishing time in addition or instead $R a$.

In summary, among criteria studied criterion LT is recommended, in which a specimen is considered to be completely polished when longitudinal roughness value coincides with transversal roughness value and, from that point on, roughness does not decrease significantly with more polishing time. Among roughness parameters considered, $R v k$ is preferred, since it ensures that previous milling marks have been completely removed.

\section{Conclusions}

Main conclusions of the present work are summarized next:

- $\quad$ For previously ball end milled or side milled samples, study of the behavior of roughness parameters with polishing time has shown that parameters $R a, R t$ and $R k$, decrease according to an exponential function. Parameter Rpk decreases sharply during the first stages of the polishing test, and parameter $R v k$ first increases slightly and then decreases. Parameter $R k u$ first increases and then decreases, while Rsk decreases and afterwards increases with time. Similar results were obtained for the two materials that were tested, namely hardened steel and hardened stainless steel.

- When determining the end of a polishing test, it is recommended not to measure roughness in one direction, but to take into account two directions, which are parallel and perpendicular to the tool marks produced by the previous machining operation respectively. Depending on the measuring direction initial roughness values will be different, and the polishing time that is necessary to remove previous marks will vary.

- After comparing results of polishing tests in the longitudinal and in the transversal direction, a new criterion is presented in order to determine the end of a polishing test, according to which a sample is considered to be polished when both longitudinal and transversal roughness values coincide, provided that roughness does not significantly decrease with polishing time.

- Regarding roughness parameters to be considered in order to determine the end of a polishing test, it is recommended to use parameter $R v k$ in addition to or even instead $R a$. $R v k$ gives additional information about the presence of marks from the previous milling operation after polishing. 


\section{Acknowledgements}

The authors thank Spanish Ministry of Education and Science for financial help of Project DPI2007-66546, as well as Mr. Ramón Casado-López/Mr. Alejandro Domínguez-Fernández for helping with experimental tests.

\section{References}

[1] Özel, T.; Liu, X. Investigations on Mechanics-Based Process Planning of Micro-End Milling in Machining Mold Cavities. Materials and Manufacturing Processes 2009, 24 (12), 1274-1281.

[2] Bassoli, E.; Minetola, P.; Salmi, A. High-Speed Milling of Tool Steel Dies for Aluminium Extrusion: Surface Roughness, Dimensional Tolerance and Chip Removal Mechanisms. Materials and Manufacturing Processes 2011, 26 (5), 764-769.

[3] Chen, J.-S.; Huang, Y.-K.; Chen, M.-S. Feedrate optimization and tool profile modification for the highefficiency ball-end milling process. International Journal of Machine Tools \& Manufacture 2005, 45, 1070 6.

[4] Vivancos, J.; Luis, C.J.; Ortiz, J.A.; González, H.A. Analysis of factors affecting the high-speed side milling of hardened die steels. Journal of Materials Processing Technology 2005, 162-3, 696-701.

[5] Zhong, Z.W. Recent advances in polishing of advanced materials. Materials and Manufacturing Processes 2008, 23 (5), 449-56.

[6] Bigerelle, M.; Giljean, S.; Mathia, T.G. Multiscale characteristic lengths of abraded surfaces: Three stages of the grit-size effect. Tribology International 2011, 44, 63-80.

[7] Lin, S.-C.; Wu, M.-L. A study of the effects of polishing parameters on material removal rate and nonuniformity. International Journal of Machine Tools \& Manufacture 2002, 42, 99-103.

[8] Chang, K.-Y.; Song, Y.-H.; Lin, T.-R. Analysis of lapping and polishing of a gauge block. Internatioanl Journal of Advanced Manufacturing and Technology 2002, 20, 414-9.

[9] Huang, M.F.; Lin, T.R.; Chiu, H.C. Effect of machining characteristics on polishing ceramic blocks. International Journal of Advanced Manufacturing and Technology 2005, 26, 999-1005.

[10] Mohan, R.; Ramesh Babu, N. Ultrafine Finishing of Metallic Surfaces with the Ice Bonded Abrasive Polishing Process. Materials and Manufacturing Processes 2012, 27 (4), 413-420.

[11] Sun, Y.; Zuo, D.; Zhu, Y.; Li, J. Using Taguchi Method to Optimize Polishing Parameters in Ice Fixed Abrasive Polishing. Materials and Manufacturing Processes 2013, 28 (8), 923-927.

[12] Wu, B.H.; Wang, J.-JJ. A neuro-fuzzy approach to generating mold/die polishing sequences. Journal of materials Processing Technology 2009, 209, 3241-50.

[13] De Chiffre, L.; Hansen, H.N.; Bronstein, A. Investigation on the surface topography in polishing using atomic force microscopy. CIRP Annals - Manufacturing Technology 1996, 45, 523-5.

[14] Grzesik, W.; Żak, K. Modification of surface finish produced by hard turning using superfinishing and burnishing operations. Journal of materials Processing Technology 2012, 212, 315-22.

[15] Vivancos, J.; Luis, C.J.; Costa, L.; Ortiz, J.A. Optimal machining parameters selection in high speed milling of hardened steels for injection moulds. Journal of Materials Processing Technology 2004, 155-156, $1505-12$.

[16] Buj-Corral, I.; Vivancos-Calvet, J.; Domínguez-Fernández, A. Surface topography in ball-end milling processes as a function of feed per tooth and radial depth of cut. International Journal of Machine Tools \& Manufacture 2012, 53, 151-9. 
[17] ISO. ISO 13565-2:1996. Geometrical Product Specifications (GPS) -- Surface texture: Profile method; Surfaces having stratified functional properties -- Part 2: Height characterization using the linear material ratio curve 1996, 1-6.

[18] Grzesik, W. Advanced Machining Processes of Metallic Materials. Theory, Modelling and Applications. Chapter Twenty - Surface Integrity; Elsevier: Amsterdam, 2008; pp. 405-426.

[19] Kumar R.; Prakash B.; Sethuramiah A. A systematic methodology to characterise the running-in and steady-state wear processes. Wear 2002, 252, 445-53.

[20] Griffiths, B. Manufacturing Surface Technology: Surface Integrity \& Functional Performance; CRC Press: New York, 2001; 237 pp.

\section{FIGURE CAPTIONS}

Figure 1 Schematic representation of: a) ball-end milling operation, b) side milling operation.

Figure 2. Surface topography and transversal roughness profiles for experiments: a) $1 \mathrm{~S}$, b) $2 \mathrm{~S}$, c) $3 \mathrm{~S}$, d) $4 \mathrm{~S}$, e) $5 \mathrm{~S}, \mathrm{f}) 6 \mathrm{~S}$.

Figure 3. Evolution of height roughness parameters with time, for all experiments considered: a) $R a$ longitudinal, b) $R a$ transversal, c) Rt longitudinal, d) $R t$ transversal

Figure 4. Evolution of roughness bearing area parameters with time, for all experiments considered: a) $R k$ longitudinal, b) $R k$ transversal, c) $R p k$ longitudinal, d) $R p k$ transversal, e) $R v k$ longitudinal, f) $R v k$ transversal Figure 5. Evolution of amplitude distribution roughness parameters with time in the transversal direction, for all experiments considered: a) $R k u$, b) $R s k$

Figure 6. Abbott-Firestone curves in the transversal direction for experiments: a) $1 \mathrm{~S}$, b) $2 \mathrm{~S}$, c) $3 \mathrm{~S}$, d) $4 \mathrm{~S}$, e) $5 \mathrm{~S}$, f) $6 \mathrm{~S}$

Figure 7. Evolution of roughness Ra for experiments: a) $1 \mathrm{~S}$ and 1I, b) $2 \mathrm{~S}$ and 2I, c) $3 \mathrm{~S}$ and $3 \mathrm{I}$, d) $4 \mathrm{~S}$ and $4 \mathrm{I}$, e) $5 \mathrm{~S}$ and $5 \mathrm{I}, \mathrm{f}) 6 \mathrm{~S}$ and $6 \mathrm{I}$

Figure $8.40 \mathrm{x}$ photographs of experiment $2 \mathrm{~S}$ at different polishing times: a) 0s, b) $10 \mathrm{~s}$, c) $20 \mathrm{~s}$, d) $30 \mathrm{~s}$, e) $40 \mathrm{~s}$, f) $50 \mathrm{~s}, \mathrm{~g}) 60 \mathrm{~s}$

\section{TABLE CAPTIONS}

Table 1. Experiments performed

Table 2. Polishing time $\mathrm{t}(\mathrm{s})$ according to criteria LT, L and T 